\title{
Lower Hybrid System Design for the Tokamak Physics Experiment
}

\author{
P. L. Goranson, D. L. Conner, D. W. Swain, and J. J. Yugo \\ Oak Ridge National Laboratory, Oak Ridge, TN 37831 \\ S. Bernabei and N. Greenough \\ Princeton Plasma Physics Laboratory, Princeton, NJ
}

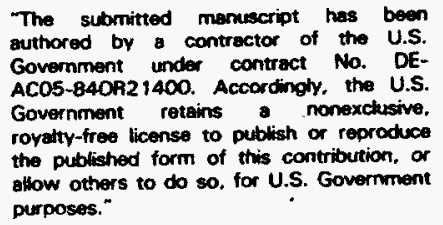

\section{DISCLAIMER}

This report was prepared as an account of work sponsored by an agency of the United States Government. Neither the United States Government nor any agency thereof, nor any of their employees, makes any warranty, express or implied, or assumes any legal liability or responsibility for the accuracy, completeness, or usefulness of any information, apparatus, product, or process disclosed, or represents that its use would not infringe privately owned rights. Reference herein to any specific commercial product, process, or service by trade name, trademark, manufacturer, or otherwise does not necessarily constitute or imply its endorsement, recommendation, or favoring by the United States Government or any agency thereof. The views and opinions of authors expressed herein do not necessarily state or reflect those of the United States Government or any agency thereof. 


\title{
Lower Hybrid System Design for the Tokamak Physics Experiment
}

\author{
P. L. Goranson, ${ }^{*}$ D. L. Conner, ${ }^{*}$ D. W. Swain, ${ }^{*}$ and J. J. Yugo* \\ Oak Ridge National Laboratory, Oak Ridge, TN 37831 \\ S. Bernabei and N. Greenough \\ Princeton Plasma Physics Laboratory, Princeton, NJ
}

\begin{abstract}
The lower hybrid (LH) launcher configuration has been redesigned to integrate the functions of the vertical four-way power splitter and the front waveguide array (front array). This permits 256 waveguide channels to be fed by only 64 waveguides at the vacuum window interface. The resulting configuration is a more compact coupler, which incorporates the simplicity of a multijunction coupler while preserving the spectral flexibility of a conventional lower hybrid launcher. Other spin-offs of the redesign are reduction in thermal incompatibility between the front array and vacuum windows, improved maintainability, in situ vacuum window replacement, a reduced number of radio frequency (rf) connections, and a weight reduction of $7300 \mathrm{~kg}$. There should be a significant cost reduction as well.
\end{abstract}

Issues associated with the launcher design and fabrication have been addressed by a research and development program

\footnotetext{
* Research sponsored by the Office of Fusion Energy, U.S. Department of Energy, under contract DE-AC05-840R21400 with Lockheed Martin Energy Systems, Inc.
}

that includes brazing of the front array and testing of the power splitter configuration to confirm that phase errors due to reflections in the shorted splitter legs will not significantly impact the rf spectrum. The Conceptual Design Review requires that radiation levels at the torus radial port mounting flange and outer surface of the toroidal field coils should be sufficiently low to permit hands-on maintenance. Low activation materials and neutron shielding are incorporated in the launcher design to meet these requirements.

The launcher is configured to couple $3 \mathrm{MW}$ of steady state $\mathrm{LH}$ heating/LH current drive power at $3.7 \mathrm{GHz}$ to the Tokamak Physics Experiment plasma.

\section{MECHANICAL DESIGN DESCRIPTION}

Neutronic analysis has been performed [1][2], which indicates that staggering waveguides to reduce neutron streaming is not necessary; the result is that the overall height is reduced and the launcher can fit into any of the standard Tokamak Physics Experiment (TPX) ports. A perspective view of the launcher may be seen in Fig. 1. An elevation cut is shown in Fig. 2. It

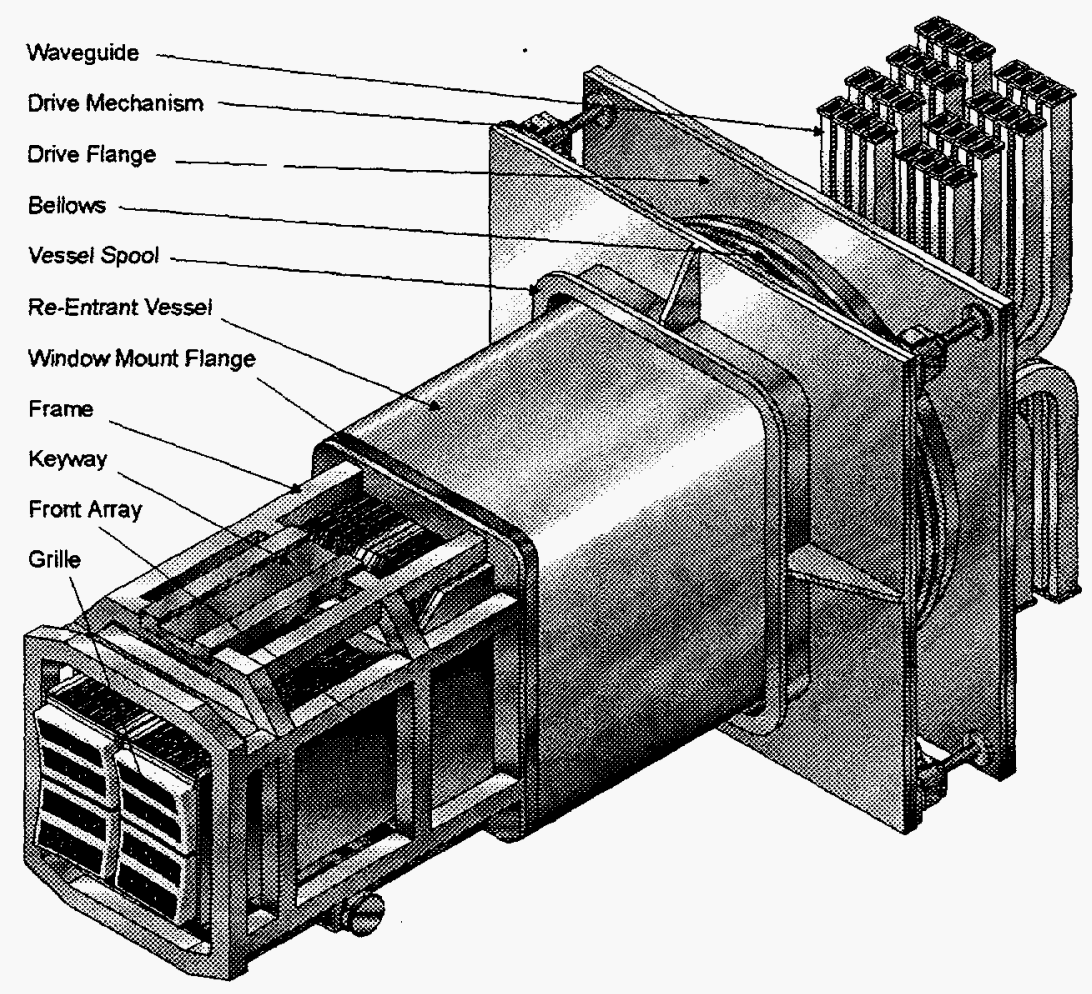

Fig. 1 Isometric view of $\mathrm{LH}$ launcher. 


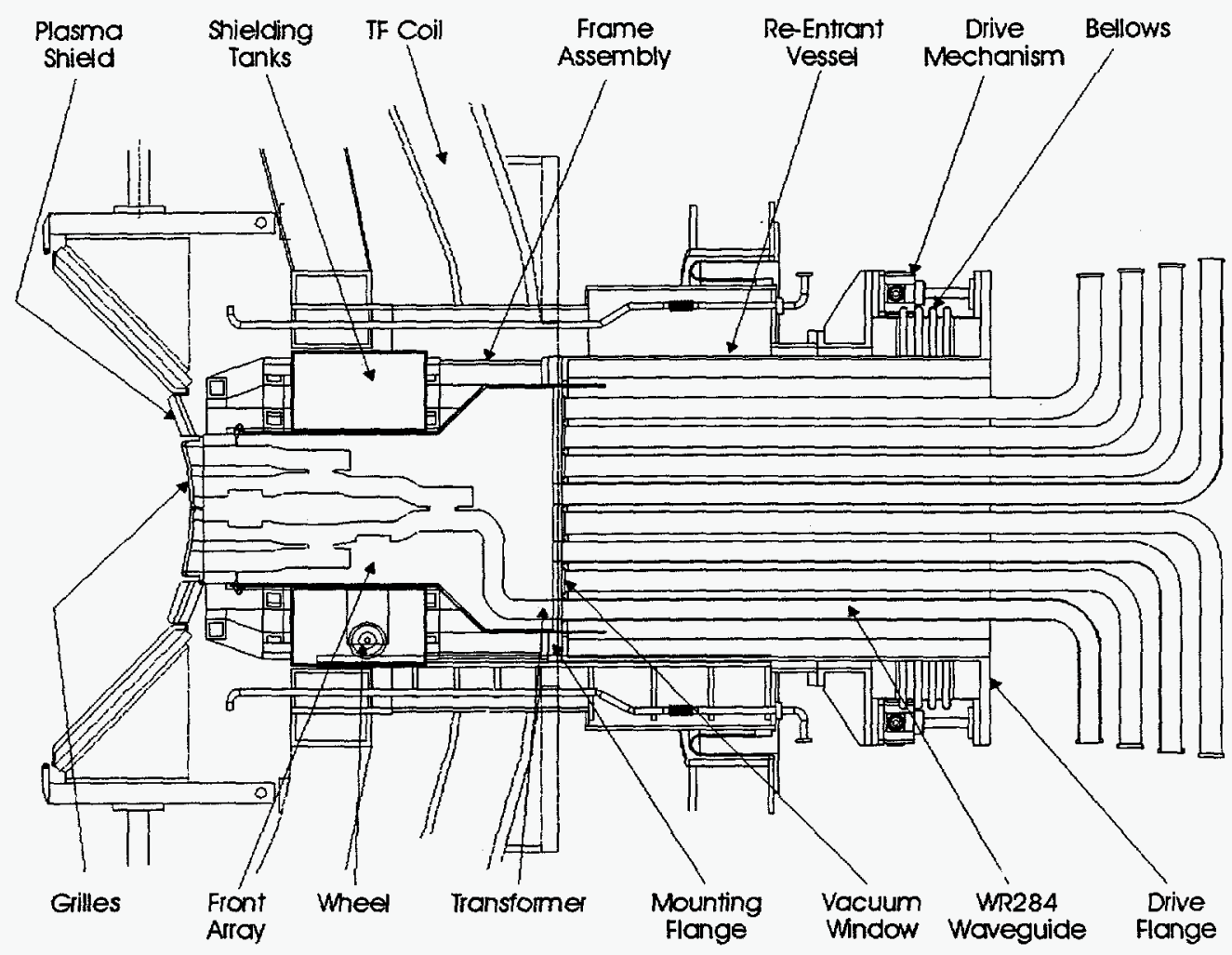

Fig. 2 Elevation cut through LH launcher.

is a radially moveable unit supported by wheels at the front (plasma end) and restrained radially by a set of four positioning screw drive units at the port end, which react loads into the vessel through the vacuum vessel flange. The launcher is isolated from vacuum by a single bellows at the cryostat mounting flange. A reentrant vessel moves the vacuum interface within the vessel port at the vacuum window. A framework constructed of low-activation titanium alloy serves as a backbone structure to tie together and hold the various components.

Keyways on the front top and bottom of the launcher frame react the torsional and vertical disruption loads into the vessel wall. The dead weight of the launcher is held by the wheels at the front and by the vessel port at the rear.

Reduction in the TPX operating temperature permits the use of water as neutron shielding, further reducing cost and complexity. Tanks of water shielding are provided to fill the gaps between the launcher and the port walls.

\section{COMPONENT DESIGN}

The plasma-facing grille is divided into four units that are bolted onto a pair of the front array stacks. Dispersion hardened copper (DHC) was chosen because of the high thermal stresses in the septa. The results of thermal analysis may be seen in Fig. 3.
The front array is the area of major change to the design. It serves as a splitter to divide the signal twice while it physically spreads out the waveguides. This function was formerly performed by a separate unit attached to the rear of the launcher. The front array utilizes a laminated construction with brazed stacks of 32 plates, each of which have been machined with a waveguide path. The patterns are identical except for the positioning of the rear exit (window interface), which staggers in successive layers and creates eight rows of waveguide interfaces that are eight deep. Spacing at the rear of the array is sufficient to allow mechanical bolting of individual waveguides to the vacuum window units (Fig. 4). Transformers are machined into the rear of the front array to transition the 6-mm-wide waveguides out to match the 24-mm window width. Formerly the windows were an integral assembly of 16 windows brazed into a titanium frame. The titanium frame was bolted to the copper front array, and the two were thermally incompatible during bakeout. A suitable solution for this problem was never found. The small physical dimensions of the new window elements and the interface to individual waveguides virtually eliminates the thermal problems; the worst case mismatch (during bakeout) is now only $0.12 \mathrm{~mm}$. The window construction is basically a commercial design based on the WR284 configuration. The flange is machined from a titanium alloy very closely matched to the expansion coefficient of the ceramic windows. The window units have sufficient material thickness so that they could be cross-drilled for cooling, but preliminary analysis indicates that forced air cooling should be sufficient. 


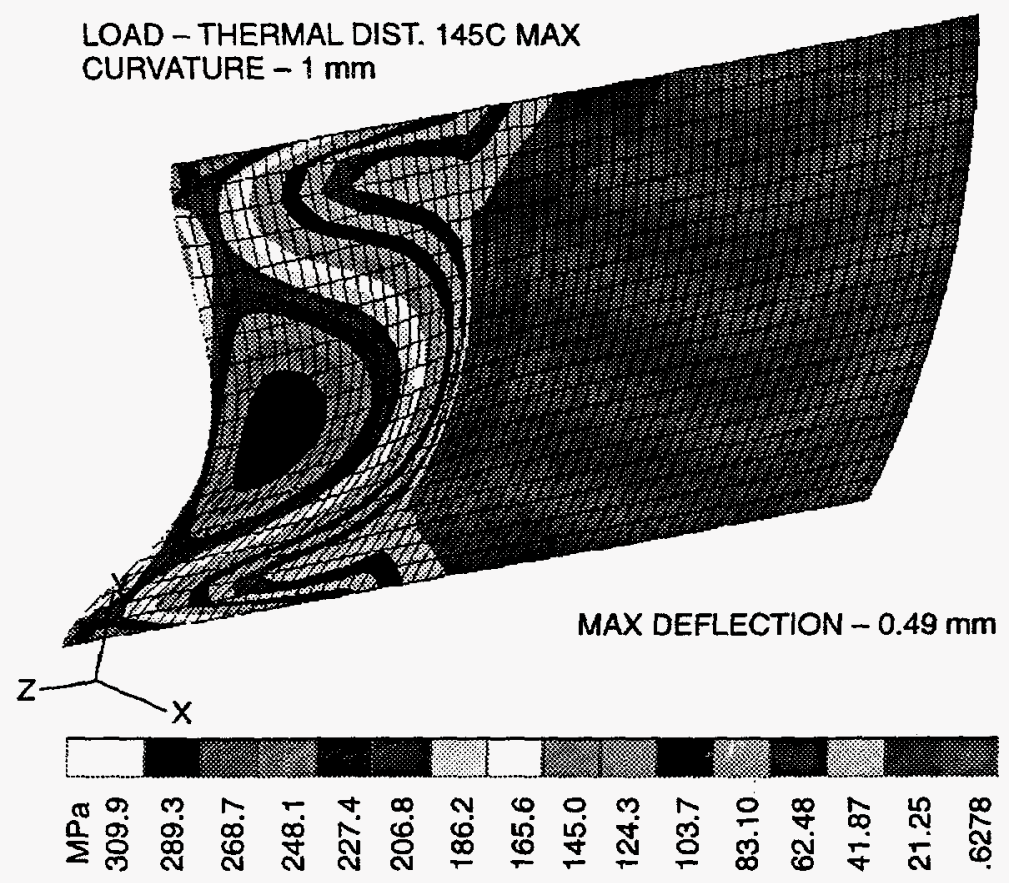

Fig. 3 Thermal stress in grille septa.

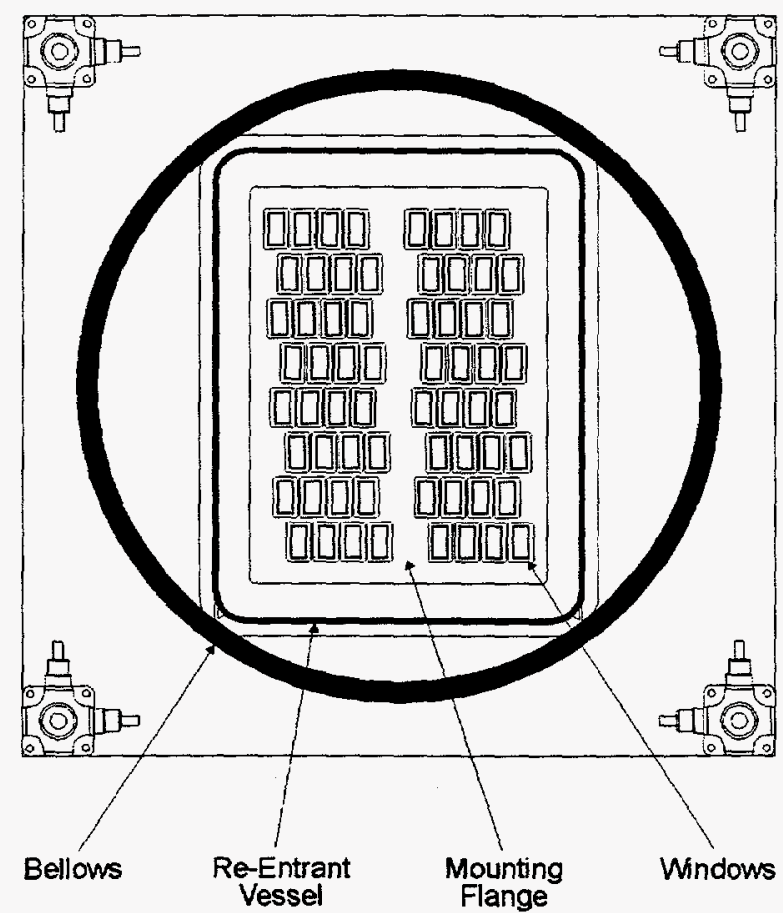

Fig. 4 Elevation cut through vacuum windows.

Water cooling is no longer necessary with the waveguides in air; commercial WR284 design units can be used. They are flanged at both ends and use metallic O-rings seals.

Behind the front array stack is an interface flange that mounts 64 individual vacuum windows and a reentrant vacuum boundary vessel. The reentrant vessel permits access to waveguide components and windows without removing the launcher or breaking the vacuum boundary.

\section{ASSEMBLY}

The front array stack is preassembled on a tooling jig and cross-drilled for coolant lines. The unit is then taken apart, cleaned, and reassembled on the jig; tubes are inserted, and the coolant headers are installed. The stack is then furnace brazed with a high-temperature braze alloy to make it water tight. The second step is to install a stainless steel flange at the rear and braze it with a lower temperature alloy. This flange serves as the vacuum interface for the reentrant vessel and as the interface for the vacuum windows. Stainless steel was chosen for thermal compatibility with the copper array and to permit a good vacuum seal with metal O-rings.

\section{MAINTENANCE}

If changeout of a launcher should become necessary, the radiation shielding is designed to permit personnel access to the vessel flange and the launcher/power splitter interface. This will allow unbolting of the flanges and disconnecting of the various utilities. The launcher front structure (grille) will be highly activated; therefore, the final removal step will require remotely rolling the assembly into a handling cask and transporting it to a hot cell.

The grille is the component subjected to the most extreme operating conditions, and it will eventually require renewal of its coating. It is designed to be easily accessible, and replacement will be possible in a hot cell. 
If a leak or short should develop in one of the window elements, replacement will be possible without removing the launcher. Access is through the vessel port flange. After removal of one or more waveguides, a long tool can be used to unbolt the window and install a replacement. The exact number of removal operations and scope of the operation for any particular window is under study. Computer modeling has demonstrated that no more than six waveguides ever have to be removed.

\section{DISRUPTION ANALYSIS}

Disruption analysis of the new configuration has shown that loads in the front array septa will not be as high as anticipated. This will permit the use of copper for the front array stack instead of DHC as previously planned. This greatly simplifies the brazing and will eliminate the need for a research and development program to evaluate means of brazing DHC in a two-step process. Results of the disruption analysis are shown in Table I [3].

Table I

Typical Disruption Loads on LH Launcher ${ }^{a}$

\begin{tabular}{llll}
\hline & Radial axis & Lateral axis & \multicolumn{1}{c}{ Vertical axis } \\
\hline Moment, $^{b} \mathrm{~N}-\mathrm{m}$ & 268,000 & 106,000 & 78,000 \\
Net force, $\mathrm{kN}$ & -5 (inward) & 42 & -80 (downward) \\
\hline
\end{tabular}

${ }^{a}$ Grille septa load $=13.7 \mathrm{kPa}$.

${ }^{b}$ Moments are summed about front, midplane face of grille.

\section{R \& D PROGRAM}

A prototype splitter (Fig. 5) was constructed and tested to optimize the geometry of the configuration. Tests were performed at low (milliwatt) power levels at $4.2 \mathrm{GHz}$ rather than $3.7 \mathrm{GHz}$, because hardware was readily available for this frequency. Dimensions were proportioned to those of the 3.7-GHz geometry to make the results applicable to TPX.

A brazing program plan [4] was prepared that will follow up on the earlier brazing tests of copper front array stacks [5]. This plan is designed to test the two-step brazing procedure by brazing prototypic coupons, complete with coolant tubes, headers, and mounting flange. At this writing, the testing was not complete.

\section{CONCERNS AND ISSUES}

The splitter configuration has been tested only at low power levels to optimize and confirm the geometry. High-power testing will be required to evaluate performance under prototypic conditions. Of particular interest will be effects of outgassing in the waveguide ducts. The two-step braze process for the front array stack is complex and needs to be confirmed before the $\mathrm{LH}$ design is considered complete. It must be demonstrated that it is possible to preassemble a stack, drill scores of cooling holes, reassemble with all the cooling tubes, and get a leaktight braze.

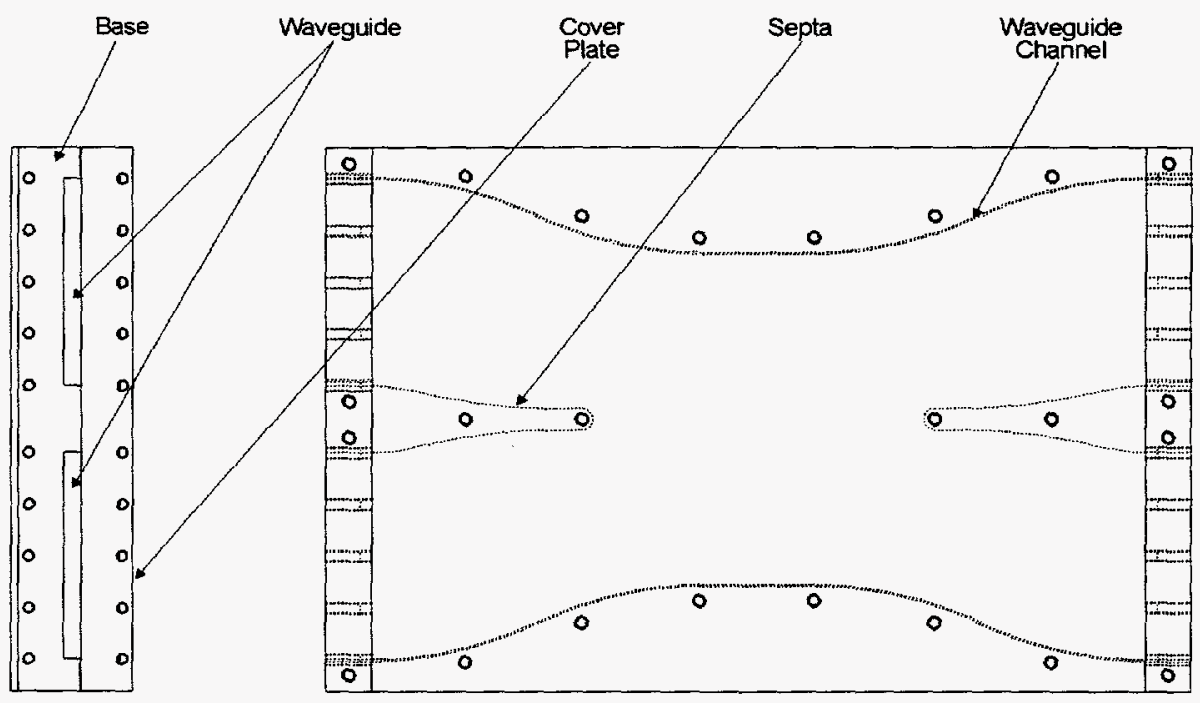

Fig. 5 Test splitter assembly.

\section{REFERENCES}

[1] L. P. Ku, "LH Radiation Shielding," Princeton Plasma Physics Laboratory, 94-940712-PPPL/LKU-01, July 1994.

[2] L. P. Ku, Activation Levels of In-vessel Components," Princeton Plasma Physics Laboratory, 94-940325-PPPL/LKU-01, March 1994.

[3] J. J. Yugo, "Disruption Analysis of TPX L.H Launcher," Princeton Plasma Physics Laboratory 24-950930-ORNL./Yugo-01.
[4] P. L. Goranson, "TPX R\&D Lower Hybrid Launcher Front Array Brazing Program," Princeton Plasma Physics Laboratory 24-950606ORNL/PGoranson-01, June 1994.

[5] P. L. Goranson, "TPX WBS 241 R\&D-Front Array Brazing Program," Princeton Plasma Physics Laboratory 24-940930-ORNL/PGoranson-01, September 1994. 